\title{
Patterns of adherence to management among patients with type 2 diabetes mellitus in South-South Region of Nigeria
}

\author{
Oyewole Oyediran Emmanuel, Agofure Otovwe ${ }^{1}$ \\ Department of Health Promotion and Education, University of Ibadan, Ibadan, ${ }^{1}$ Department of Public and Community Health, Novena University, \\ Ogume, Nigeria
}

\section{A B S T R A C T}

Aims: The study investigated the pattern of adherence to medication and dietary treatment among type 2 diabetes mellitus patients. Settings and Design: A cross-sectional study conducted among 350 consented patients with type 2 diabetes mellitus from a secondary public healthcare facility. Materials and Methods: A semistructured questionnaire was interviewer-administered to obtain information on respondents' sociodemographic characteristics, level of adherence to medication and dietary treatment, and suggestions on ways of improving adherence to treatment. Descriptive statistics, chi-square test, and logistic regression were used to analyze the data with level of significance set at $\mathbf{0 . 0 5}$. Results: Mean age of respondents was $57.9 \pm 9.8$ years, $60.9 \%$ were females and $78.0 \%$ were married. Some respondents exhibited total adherence to medication (58.9\%) and dietary (67.4\%) treatment, respectively. Determinants of nonadherence to medication and dietary treatment include using alternative traditional medicine (herbs) for the treatment of the disease (odds ratio $(O R)=0.42,95 \%$ confidence interval $(\mathrm{Cl})=0.568-1.916)$ and consuming foods more than recommended quantity $(\mathrm{OR}=6.28,95 \%$ $\mathrm{Cl}=3.919-10.083)$. One of the suggested ways by the respondents to improve adherence to treatment was self-discipline (46.9\%). Lack of awareness on the seriousness of the disease (42.6\%) was a major challenge confronting patients with type 2 diabetes mellitus. Creation of awareness on the seriousness of the disease was suggested by $39.1 \%$ of respondents. Conclusions: Use of alternative medicine (herbs) and eating more than the recommended quantity of foods remain a challenge among patients with type 2 diabetes mellitus. Comprehensive health promotion and education strategies including patient counseling on diabetes care with emphasis on adherence to medication and dietary treatment regimen should be organized regularly for diabetes patients.

Key words: Adherence, medication and dietary treatment, Type 2 diabetes mellitus

\section{INTRODUCTION}

Diabetes is the sixth leading cause of death worldwide, ${ }^{[1]}$ while the number of diabetes cases worldwide has increased significantly in the last decade. ${ }^{[2]}$ Each year, 3.2 million people around the world die from complications associated with diabetes. ${ }^{[3]}$

\begin{tabular}{|c|l|}
\hline \multicolumn{2}{|c|}{ Access this article online } \\
\hline Quick Response Code: & Website: \\
\hline & www.joshd.net \\
\hline & \\
\hline
\end{tabular}

In Africa, the traditional rural communities still have low prevalence of $1-2 \%$ (except in specific high risk groups), while $1-13 \%$ or more adults in urban communities have diabetes. ${ }^{[4,5]}$ Current prevalence rate estimates of diabetes in Nigeria have been tagged at 2.5\% compared to its $2.2 \%$ rate in $2003 .{ }^{[6]}$ Diabetes is one of the chronic illnesses for which self-management plays a central role in care, and poor management of glucose level which is paramount in developing countries like $\mathrm{Nigeria}^{[7]}$ will result in complications that will be detrimental to the patient's health.

Thus, this study was designed to investigate the pattern of adherence to medication and dietary treatment among type 2 diabetes mellitus patients.

Corresponding Author: Mr. Agofure Otovwe, C/O Department of Public and Community Health, Novena University, Ogume, Nigeria. E-mail: agofureotovwe@yahoo.com 


\section{MATERIALS AND METHODS}

A cross-sectional survey design was used for this study, involving the consented patients attending the Central Hospital based in Warri, South-South region of Nigeria, which is a secondary healthcare facility. Central Hospital is the largest referral hospital within the Warri metropolis. It operates outpatient diabetes clinic twice every week with an average of between 50 and 60 type 2 diabetes patients visiting the hospital per diabetes clinic day. The target population was all the consented male and female type 2 diabetic patients from 35 years and above who attended the outpatient diabetic clinic within the study period of 4 months (May-August). Thus, 350 type 2 diabetic patients who met the inclusion criteria were recruited for the study. The inclusion criteria were confirmed type 2 diabetes mellitus, aged at least 35 years, attending the diabetic clinic during the study period and giving informed consent to participate in the study. The questionnaire was pretested among 20 type 2 diabetes patients in another secondary hospital in a different location. After the pretesting, some questions in the questionnaire were modified and reframed to ensure validity of the instrument and facilitate patients' understanding. The final semistructured questionnaire was interviewer-administered to solicit respondents' sociodemographic characteristics, adherence to medication and dietary regimen, determinants of nonadherence to medication and dietary regimen, and ways of improving medication and dietary treatment. Cronbach alpha test reliability was used to determine the reliability of the instrument. The Cronbach alpha reliability statistics gave 0.821 . Level of adherence to medication was measured on 18-point scale graded; partial $(0-10)$ and strict $(>10)$, while level of adherence to dietary treatment was measured on a 6-point scale graded partial $(0-3)$ and strict $(>3)$. Ethical approval was obtained from Delta State Ministry of Health, Asaba. The collected data was entered into Statistical Product and Service Solutions (SPSS) version 15.0 anddescriptive statistics was used to evaluate frequency distribution, while chi-square test and logistic regression were performed to test for associations between variables of interest with level of significance set at $P<0.05$.

\section{RESULTS}

Of the 350 respondents, most were females $(n=213$, $60.9 \%)$, than males $(n=137,39.1 \%)$. Overall mean age of the respondents was $57.9 \pm 9.8$. Majority, were married $(n=273,78.0 \%)$. More than one-fourth $(n=98,28.0 \%)$ had post-secondary education, while more than one-third $(n=133,38.0 \%)$ were traders [Table 1].

Furthermore, in Table 1, 71 (20.3\%) respondents from age group 55-65 strictly adhered to medication, while almost one-fourth $(n=79,22.6 \%)$ of age group $45-54$ strictly adhered to dietary treatment. There was an association between the various age groups, educational status, and adherence to medication and dietary treatment, respectively.

As shown in Table 2, logistic regression on the determinants of nonadherence to medication treatment showed that taking alternative traditional medicines (herbs) for the

\begin{tabular}{|c|c|c|c|c|}
\hline \multirow[t]{2}{*}{ Variable } & \multirow[t]{2}{*}{$\begin{array}{l}\text { Frequency } \\
\text { (\%) }\end{array}$} & \multicolumn{2}{|c|}{$\begin{array}{l}\text { Level of adherence to medication and dietary } \\
\text { treatment }\end{array}$} & \multirow[t]{2}{*}{$P$ - value } \\
\hline & & Partial (\%) & Strict (\%) & \\
\hline \multicolumn{5}{|l|}{ Age (years) } \\
\hline $35-44$ & $29(8.3)$ & $17(4.9), 13(3.7)^{\star}$ & $11(3.1), 15(4.3)^{\star}$ & $0.03, \mathrm{~S}$ \\
\hline $45-54$ & $104(29.7)$ & $39(11.1), 26(7.4)^{\star}$ & $61(18.9), 79(22.6)^{*}$ & $0.04, S^{*}$ \\
\hline $55-64$ & $113(32.3)$ & $42(12.0), 36(10.3)^{*}$ & $71(20.3), 77(22.0)^{*}$ & \\
\hline $65-74$ & $90(25.7)$ & $41(11.7), 36(10.3)^{*}$ & $49(14.0), 54(15.4)^{*}$ & \\
\hline$>75$ & $14(4.0)$ & $5(1.4), 3(0.9)^{*}$ & $9(2.6), 11(3.1)^{*}$ & \\
\hline \multicolumn{5}{|c|}{ ) } \\
\hline Male & $137(39.1)$ & $58(16.6), 44(12.6)^{*}$ & $79(22.6), 93(26.6)^{*}$ & $0.59, \mathrm{NS}$ \\
\hline Female & $213(60.1)$ & 86 (24.6), 86 (20.0) & $126(36.3), 43(40.9)^{*}$ & $0.88, \mathrm{NS}^{*}$ \\
\hline \multicolumn{5}{|l|}{ Marital status } \\
\hline Single & $1(0.3)$ & $0(0.0), 0(0.0)^{*}$ & $1(0.3), 1(0.3)^{*}$ & $0.61, \mathrm{NS}$ \\
\hline Married & $273(78.0)$ & $111(31.7), 7(24.9)^{*}$ & $163(46.6), 187(53.4)^{*}$ & $0.62, \mathrm{NS}^{*}$ \\
\hline Widow/Widower & $76(21.7)$ & $33(9.4), 27(7.7)^{\star}$ & $42(12.0), 48(13.7)^{\star}$ & \\
\hline \multicolumn{5}{|l|}{ Educational Status } \\
\hline No formal education & $34(9.7)$ & $12(2.4), 9(2.4)^{*}$ & $22(6.3), 25(7.1)^{\star}$ & $0.02, \mathrm{~S}$ \\
\hline Primary education & 75 (21.4) & $30(8.6), 29(8.3)^{*}$ & 45 (12.9), $46(13.1)^{\star}$ & $0.01, S^{*}$ \\
\hline Secondary education & $143(40.9)$ & $57(16.3), 42(12.0)^{*}$ & $86(24.6), 101(28.9)^{*}$ & \\
\hline Tertiary education & $98(28.0)$ & $45(12.9), 34(9.7)^{*}$ & $53(15.1), 64(18.3)^{\star}$ & \\
\hline
\end{tabular}

S: Significant, NS: not significant, * Level of adherence to dietary treatment 
treatment of disease was the major contributing variable at odds ratio $(\mathrm{OR})=0.425,95 \%$ confidence interval $(\mathrm{CI})=$ 0.568-1.916, while the least was taking incomplete doses of prescribed medicine $\mathrm{OR}=11.20195 \% \mathrm{CI}=6.927-18.112$.

Similarly in Table 3, logistic regression on the determinants of nonadherence to dietary treatment showed that eating food in large quantity that should be taken in little quantity was the major contributing variable at $\mathrm{OR}=6.286,95 \%$ $\mathrm{CI}=3.919-10.083$; while the least was eating foods that one should stop taking because of the disease $\mathrm{OR}=12.010$, $95 \% \mathrm{CI}=7.422-19.435$.

Figure 1 shows the level of adherence to medication treatment, with more than half $(n=206,58.9 \%)$ strictly adhering to medication treatment. Similarly, Figure 2 shows the level of adherence to dietary treatment, with more than two-third $(n=236,67.4 \%)$ strictly adhering to dietary treatment.

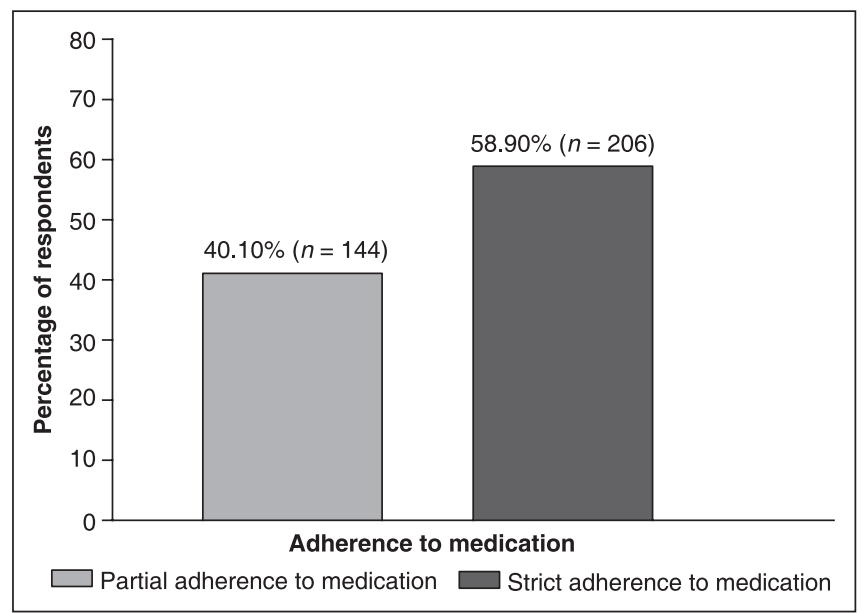

Figure 1: Level of adherence to medication treatment
As shown in Table 4, less than half $(n=164,46.7 \%)$ of respondents suggested patients exhibiting self-discipline, as a way of improving medication and dietary treatment, and the least was government should equip hospitals $(n=8,2.3 \%)$; while less than half $(n=149,42.6 \%)$ said lack of awareness about the disease was the major challenge confronting diabetic patients, and the least was food stuff is expensive $(n=4,1.1 \%)$ [Table 5]. Similarly in Table 6, more than two-third $(n=229,65.4 \%)$ suggested following recommended guidelines as a way of overcoming challenges confronting diabetic patients, while the least was doctors should prescribe drugs adequately $(n=32$, 9.1\%).

\section{DISCUSSION}

Results showed that most of the respondents were between the ages of 55 and 64 years of age, which is similar with previous studies. ${ }^{[8,9]}$ This age range might be because the

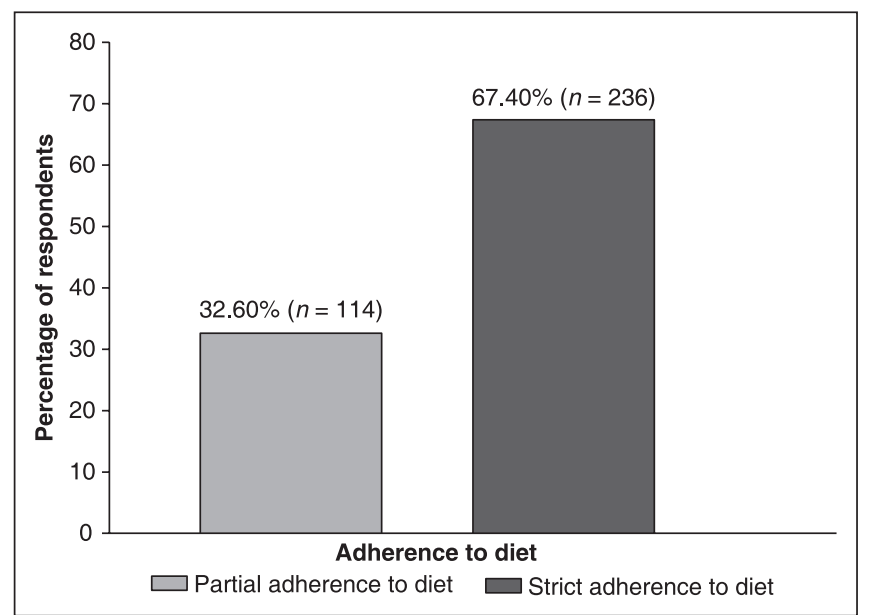

Figure 2: Level of adherence to dietary treatment

\begin{tabular}{|c|c|c|c|c|}
\hline Variables & df & $P$ - value & OR & $95 \% \mathrm{Cl}$ \\
\hline Use of alternative traditional medicines & 1 & 0.00 & 0.425 & $0.568-1.916$ \\
\hline Continuous use of drugs according to doctor's prescription & 1 & 0.00 & 4.129 & $3.861-15.625$ \\
\hline Side effects of the drug after use & 1 & 0.00 & 4.965 & $3.346-7.367$ \\
\hline Sense of well-being/healing & 1 & 0.00 & 5.347 & $3.453-8.280$ \\
\hline Forgetfulness & 1 & 0.00 & 5.487 & $3.630-8.296$ \\
\hline Skipping doses of prescribed medicine & 1 & 0.00 & 7.450 & $4.680-11.858$ \\
\hline Preference for medicines from local pharmacy store to the prescription by the physician & 1 & 0.00 & 9.991 & $6.125-16.289$ \\
\hline Taking other medicines prescribed by friends and relations & 1 & 0.00 & 10.934 & $6.782-17.628$ \\
\hline Taking incomplete doses of prescribed medicine & 1 & 0.00 & 11.201 & 6.927-18.112 \\
\hline
\end{tabular}

df: Degrees of freedom, OR: Odds ratio, Cl: Confidence interval

\begin{tabular}{lcccc}
\hline Table 3: Determinants of nonadherence to dietary treatment & & & \\
\hline Variables & df & $\boldsymbol{P}$ - value & OR & $\mathbf{9 5 \%}$ Cl \\
\hline Eating food in large quantity that should be taken in little quantity & 1 & 0.00 & 6.286 & $3.919-10.083$ \\
Faith healing preventing one from adhering to recommended diet & 1 & 0.00 & 9.904 & $6.244-15.710$ \\
Eating foods that one should stop taking because of the disease & 1 & 0.00 & 12.010 & $7.422-19.435$ \\
\hline
\end{tabular}
df: Degrees of freedom, OR: Odds ratio, Cl: confidence interval 


\begin{tabular}{lcc}
\hline $\begin{array}{l}\text { Table 4: Respondent's view on ways of improving } \\
\text { medication and dietary treatment }\end{array}$ & $\begin{array}{c}\text { Frequency } \\
(\boldsymbol{n}=\mathbf{7 0 0})^{\star *}\end{array}$ & $\begin{array}{c}\text { Percent } \\
\text { (\%) }\end{array}$ \\
\hline Variable & 140 & 40.0 \\
& & \\
\hline Patients should seek more information about & 139 & 39.7 \\
the disease & 139 & 39.7 \\
Health care should be easily accessible & 164 & 46.7 \\
Stick to doctors instructions & 49 & 14.0 \\
Patients should exhibit self-discipline & 67 & 19.1 \\
Patients should attend hospital regularly & & \\
Regular workshop on diabetic education & 54 & 15.4 \\
should be organized & 55 & 15.7 \\
Government should help in subsidizing the drugs & 31 & 8.9 \\
Pray to God for help & 47 & 13.4 \\
Find the cure for the disease & 46 & 13.1 \\
Free treatment & 34 & 9.7 \\
Availability of drugs & 22 & 6.3 \\
Taking drugs regularly & 18 & 5.1 \\
Creation of awareness & 8 & 2.3 \\
Regular counseling & & \\
Government should equip hospitals &
\end{tabular}

**Multiple responses

\begin{tabular}{lcc}
\hline Table 5: Major challenges confronting diabetes patients \\
\hline Variable & $\begin{array}{c}\text { Frequency } \\
(\boldsymbol{n}=\mathbf{7 0 0})^{\star *}\end{array}$ & $\begin{array}{c}\text { Percent } \\
(\%)\end{array}$ \\
\hline Lack of awareness about the disease & 149 & 42.6 \\
Age of patients and what they feel and go through & 126 & 36.0 \\
Stigma in mixing with friends and relations & 73 & 20.9 \\
Restriction in drinking and eating & 118 & 33.7 \\
Financial constraint & 76 & 21.7 \\
Nonchalancy and carelessness on the part & 92 & 26.3 \\
of patients & 121 & 34.6 \\
Individual differences/belief & 132 & 37.7 \\
Ignorance on the importance of adhering & & \\
to treatment & 89 & 25.4 \\
Burden of ingesting and injecting drugs & 7 & 2.0 \\
Counterfeit drugs in the system often & & \\
discourage diabetes patients & 4 & 1.1 \\
Food stuff is expensive & &
\end{tabular}

\begin{tabular}{lcc}
\hline $\begin{array}{l}\text { Table 6: Respondent's view of overcoming challenges } \\
\text { confronting diabetes patients }\end{array}$ & $\begin{array}{c}\text { Frequency } \\
(\boldsymbol{n}=\mathbf{7 0 0})^{\star *}\end{array}$ & $\begin{array}{c}\text { Percent } \\
\mathbf{( \% )}\end{array}$ \\
\hline Variable & 137 & 39.1 \\
& 97 & 27.7 \\
\hline Creation of more awareness about the disease & 77 & 22.0 \\
Conditions of diabetic patients should be improved & & \\
Patients should be realistic and show strong & 69 & 19.7 \\
will to adhere & 57 & 16.3 \\
$\begin{array}{l}\text { Praying to God for help } \\
\text { Financial support from the government and }\end{array}$ & 40 & 11.4 \\
relations & & \\
$\begin{array}{l}\text { Diabetic patients should prepare adequately } \\
\text { before leaving home to avoid temptation }\end{array}$ & 229 & 65.4 \\
$\begin{array}{l}\text { Following recommended guidelines } \\
\text { Empower diabetic patients with knowledge }\end{array}$ & 91 & 26.0 \\
$\begin{array}{l}\text { on management of the disease } \\
\text { Attending clinic regularly }\end{array}$ & 49 & 14.0 \\
$\begin{array}{l}\text { Counseling on the need to adhere to treatment } \\
\text { Proper management of finance when it is }\end{array}$ & 79 & 22.6 \\
$\begin{array}{l}\text { available } \\
\text { Doctors should prescribe drugs adequately }\end{array}$ & 19 & 5.4 \\
**Multiple responses & 32 & 9.1 \\
\hline
\end{tabular}

study focuses on type 2 diabetes mellitus, which is usually adult onset. Also, most of the respondents were females and traders which is consistent with the study location were majority of traders are females.

Linda ${ }^{[10]}$ reported that sociodemographic variables such as age, gender, and race appear to influence the degree of adherence to medication and dietary treatment. However, age and educational status had a significant association with both adherence to medication and dietary treatment; while sex, marital status, and occupation had no association with both adherence to medication and dietary treatment. This is similar to previous findings where age and educational status had a significant association with adherence to treatment, ${ }^{[7]}$ while contrary to the same findings by Okolie et al., ${ }^{[7]}$ were sex, marital status, and occupation had a significant association with adherence to treatment.

The level of adherence from the study showed above average for strict and partial adherence to medication treatment which is consistent with previous studies. ${ }^{[10,12]}$ Also, taking alternative traditional medicines (herbs) for the treatment of the disease was the major determinant variable contributing to nonadherence to medication treatment. This use of alternative traditional medicine might be due to the perceived inefficacy of orthodox medicine and the easy access to traditional herbs which are usually obtained from traditional healers and local herb dealers.

Similarly, the level of adherence from the study showed above average for strict and below average for partial adherence to dietary treatment which is consistent with previous studies. ${ }^{[10-12]}$ In addition, eating food in large quantity that should be taken in little quantity was the major determinant variable contributing to nonadherence to dietary treatment. This finding might be due to respondents from the study location having difficulty in adjusting to little or moderate carbohydrate intake, which is the main staple food of the people. This finding is similar to previous findings where respondents had difficulty in adjusting to dietary treatment. ${ }^{[8,12]}$

Respondent's view of improving adherence to medication and dietary treatment is self-discipline by diabetic patients which shows the role of self-management in managing the disease and preventing complications associated with diabetes. ${ }^{[7]}$

Furthermore, lack of awareness about the disease was the major challenge confronting diabetic patients indicating the importance of improving access to 
information about the disease which is vital in its successful management. ${ }^{[8]}$ This was corroborated by majority of the respondents who suggested following recommended guidelines and creation of more awareness about the disease as ways of overcoming challenges confronting diabetic patients.

\section{CONCLUSION}

In most part of Nigeria, use of herbs for treatment of diseases and eating of food composed mainly of carbohydrate as staple meal is common. Thus, respondents in the study had a challenge of use of alternative medicine (herbs) and eating food above recommended quantity. Therefore, health education on diabetic care with emphasis on adherence to medication and dietary treatment regimen, among other strategies, should be organized regularly for diabetic patients.

\section{REFERENCES}

1. Morbidity Mortality Weekly Report. Social Economic Status of women with diabetes United States 2000. A CDC weekly Report, Retrieved October 19; 2008.

2. Zeck W, McIntyre HD. Gestational diabetes in rural East Africa: A call to action. J Womens Health (Larchmt) 2008;17:403-11.

3. International Diabetes Federation, Diabetes atlas. Diabetes facts, $2^{\text {nd }}$ and $3^{\text {rd }}$. Available from: http://www.worlddiabetesfoundation. org/composite-35.htm [Last accessed on 2006 Apr 7]
4. Sobngwi E, Maurvais-Jarvis F, Mbanya JC. Diabetes in Africa: Part 1: Epidemiology and clinical specifities in all Africa.com/stories; 2007.

5. Kolawole BA, Adegbenro C, Ayoola ZO, Opebiyi B. Diabetes mellitus related treatment goals: Awareness and attainment in the Ife-ljesa zone of south-western Nigeria. Afr J Med Med Sci 2005;34:389-94.

6. World Health Organization, African Region: Nigeria. 2009. [Last accessed on 2009 Mar 4].

7. Okolie U, Ehiemere I, Ezenduka P, Ogbu S. Contributory factors to Diabetes dietary regimen non adherence in adults with diabetes. Wor Acad Sci Engin Tech 2010;69:743-1.

8. Nguma LK. Health seeking and related behavior for type 2 diabetes mellitus among adults in urban community in Tanzania PhD. Thesis. University of Otago; 2010. p. 349.

9. Yusuff KB, Obe O, Joseph BY. Adherence to anti-diabetic drug therapy and self management practices among type 2 diabetics in Nigeria. Pharm World Sci 2008;30:876-83.

10. Linda CC. Health education and Health promotion. In: Suzame CS, Brenda GB, editors. Brunner and Sudddarth's Textbook of Medical Surgical Nursing. $10^{\text {th }}$ ed. Philadelphia: Lippincott William and Wilkins; 2004. p. 46-7.

11. King H, Aubert RE, Herman W. Global burden of diabetes, 19952025: Prevalence, numerical estimates, and projections. Diabetes Care 1998;21:1414-31.

12. Wabe NT, Angamo MT, Hussein S. Medication adherence in diabetes mellitus and self-management practices among type-2 diabetics in Ethiopia. N Am J Med Sci 2011;3:418-23.

How to cite this article: Emmanuel OO, Otovwe A. Patterns of adherence to management among patients with type 2 diabetes mellitus in SouthSouth Region of Nigeria. J Soc Health Diabetes 2015;3:115-9.

Source of Support: Nil. Conflict of Interest: None declared. 